\title{
Effect of a Home-based Exercise Program on Elderly Women's Health
}

\author{
Hyo-Lyun Roh, PhD, PT ${ }^{1)}$, Dae-Hee Lee, PhD, $\mathrm{PT}^{2)}$ \\ 1) Department of Occupational Therapy, Kangwon National University \\ 2) Department of Physical Therapy, Youngdong University: 12-1 Seolgye-ri, YeongDong-eup, \\ YeongDong-gun, ChungBuk, 370-701 Republic of Korea. \\ TEL: +82 43-740-1402,FAX: +82 43-740-1109,E-mail: bobath99@hanmail.net
}

\begin{abstract}
Purpose] This study's purpose was to determine the effects of a home-based exercise program on functional fitness and total cholesterol in elderly women. [Methods] Twenty-two elderly women were divided into an exercise group (12 females; average age: 71.00 years; average height: $151.75 \mathrm{~cm}$; average weight: $55.05 \mathrm{~kg}$ ) and a control group (10 females; average age: 72.42; average height: $149.71 \mathrm{~cm}$; average weight: $58.14 \mathrm{~kg}$ ) and the exercise group performed a home-based exercise program three times per week for 8 weeks. For the exercise program, a 10-minute warm-up, 40-minute main exercise, and 10-minute cool-down were conducted. Functional fitness (upper extremity muscle strength, lower extremity muscle strength, upper extremity flexibility, lower extremity flexibility, static balance, and cardiorespiratory endurance) and total cholesterol were measured prior to and after the exercise intervention. [Results] The exercise group, which performed the home-based exercise program, showed improvements in their upper and lower extremity muscle strengths, flexibility, and cardiorespiratory endurance. On the other hand, the upper extremity flexibility, static balance, and cardiorespiratory endurance of the control group decreased. There were no significant changes in total cholesterol in either group. [Conclusion] Proper guidance is necessary to ensure elderly people continue to exercise independently after an exercise program ends, since it is important for elderly people in the local community to engage in exercise on their own, even if it only consists of simple exercises.
\end{abstract}

Key words: Home-based exercise, Elderly women's health

(This article was submitted Dec. 1, 2011, and was accepted Jan. 9, 2012)

\section{INTRODUCTION}

As elderly people grow older, their muscle strength weakens ${ }^{1)}$, balance ability declines ${ }^{2}$, and cardiorespiratory endurance decreases ${ }^{3)}$. Exercise has physical, psychological, and social benefits and regular physical activities enhance cardiovascular system function ${ }^{4)}$, muscle strength, muscle endurance, alertness, flexibility, and cardiorespiratory function. It also helps to maintain blood pressure, pulse, respiration, and blood glucose level within normal ranges $^{5}$. However, according to the 2007 Korea Health Statistics, elderly individuals' rates of vigorous physical activity decreases as they grow older, and in particular, elderly women's physical activity levels are very low ${ }^{6}$. Additionally, Korea lacks spaces where elderly people can conveniently exercise as well as facilities and environments where scientific exercise programs can be provided. The public sector is in charge of managing chronic diseases in the low-income elderly population, and some daycare and social welfare centers provide the elderly with diverse intervention programs for their leisure or recreational activities. Nonetheless, the intervention programs are not approached in a comprehensive manner; rather they are operated to meet program targets. Therefore, meaningful results in individual health changes are not being sufficiently produced ${ }^{7)}$. Moreover, members-only fitness clubs or other spaces with convenient facilities are available only to an extremely small number of people; therefore, elderly people with little economic power are excluded ${ }^{8)}$. As such, an exercise program considering elements such as exercise intensity and time, total exercise amount, and the environment, as well as facility, spatial, and economic constraints need to be developed ${ }^{9)}$, to enable easy access and use by elderly people in the local community ${ }^{10)}$. Accordingly, this study examined elderly women's changes in functional fitness and total cholesterol after performance of a home-based exercise program.

\section{SUBJECTS AND METHODS}

This study used a nonequivalent control group pre-post test design. The subjects were elderly women (65 or older) who were attending a local health care center for treatment of mild diseases such as colds, abdominal pain, and bruises. To be included, participants were required to have the following: the ability to engage in activities of daily living and walk outdoors independently, no pain or functional abnormalities that could restrict their participation in the exercise program, 
Table 1. Home-based exercise program stages

\begin{tabular}{|c|c|c|c|c|c|c|}
\hline $\begin{array}{l}\text { Training } \\
\text { Period } \\
\text { (week) }\end{array}$ & $1-3$ & & $4-6$ & & $7-8$ & \\
\hline $\begin{array}{l}\text { Training } \\
\text { Program }\end{array}$ & Group exercise & Home exercise & Group exercise & Home exercise & Group exercise & Home exercise \\
\hline $\begin{array}{l}\text { Frequency } \\
\text { (days/week) }\end{array}$ & 3 & 0 & 2 & 1 & 1 & 2 \\
\hline $\begin{array}{l}\text { Exercise } \\
\text { program }\end{array}$ & warm up exercise & cool down & warm up exercise & cool down & warm up exercise & cool down \\
\hline
\end{tabular}

and no neurological damage, severe cardiovascular system diseases, unstable chronic or end-stage diseases, severe depression, serious cognitive damage, or musculoskeletal system damage. The study was explained and consent was obtained from those who intended to voluntarily participate in this study. The subjects were randomly assigned to an exercise group (15) and a control group (14). A total of 12 subjects in the exercise group (age $71.00 \pm 7.34$, height $151.75 \pm 3.97 \mathrm{~cm}$, weight $55.05 \pm 7.78 \mathrm{~kg}$, body mass index $23.90 \pm 3.26 \mathrm{~kg} / \mathrm{m}^{2}$ ), and 10 in the control group (age 72.42 \pm 3.10 , height $149.71 \pm 4.75 \mathrm{~cm}$, weight $58.14 \pm 5.11 \mathrm{~kg}$, body mass index $25.94 \pm 2.30 \mathrm{~kg} / \mathrm{m}^{2}$ ) were assessed before and after the exercise intervention and participated in the entire study. The study period spanned 8 weeks from July to August 2010. The home-based self-exercise program was performed only by the exercise group, three times per week, and the control group did not perform any regular exercise for health improvement.

The home-based exercise program was composed of three-stages, aimed at continuous performance at home (Tables 1,2). The exercise group gathered at a local health care center and performed group exercise together; subjects in this group also conducted a self-exercise program they were trained to perform at home. They gradually increased the frequency of their home exercise. During the first stage (weeks 1 to 3), they exercised as a group three times per week; during the second stage (weeks 4 to 6), they exercised as a group twice per week and then exercised at home once per week, and during the third stage (weeks 7 and 8), they exercised as a group once per week and twice per week at home.

For the exercise program, a 10-minute warm-up, a 40-minute main exercise, and a 10-minute cool-down were conducted. New Millennium Gymnastics was modified and performed for the warm-up and the cool-down, which consisted of flexibility exercises, and walking in place exercises. New Millennium Gymnastics is an exercise that anyone, regardless of gender or age, can easily perform without special tools or spatial constraint. It was developed in 1999 by the Seoul Olympic Sports Promotion Foundation by adapting traditional music, dances, and military arts. The exercises used in this study consisted of arm, leg, waist, side, trunk, neck and respiration exercises, with the main focus on large joint movements. The flexibility exercises consisted of upper and lower extremity stretching. The main exercise portion of the program was made up of exercises recom- mended by the National Institute on Aging for improving lower extremity muscle strength and balance ability ${ }^{11)}$, and the subjects were instructed to practice these exercises to music in order to engage their interest and induce continuous participation in the exercises. The exercise intensity was adjusted so that the activities felt "a little hard" based on Borg's Ratings of Perceived Exertion Scale (1998) ${ }^{12)}$. During the first stage, the elderly subjects practiced all of the motions with no resistance, and from the second stage on, $0.5 \mathrm{~kg}$ sand bags were used to gradually increase resistance. For better adaptability to the home exercise program, an exercise instructor directed the subjects to complete the exercise program over the phone and then confirmed subjects' performance. Exercise videos, music tapes, and sand bags were provided so they could perform self-exercise in the same manner as group exercise and they were instructed to keep an exercise journal to accurately record whether they exercised. The exercise instructor educated the subjects and coached them on accurate and safe exercise during their workouts. As another safety measure, the instructor also installed a chair next to the subjects so that they could hold it, if it was needed, to prevent themselves from falling.

Both groups' functional fitness and total cholesterol were measured prior to the exercise and after 8 weeks of exercise. For precise measurement, they were assessed under a trained physical therapist's guidance. For functional fitness measurements, subjects' muscle strength, upper and lower extremity flexibilities, static balance ability, and cardiorespiratory endurance were measured. Grip force was measured to evaluate upper extremity muscle strength as well ${ }^{13)}$. To accomplish this, subjects stood with their feet shoulderwidth apart and their arms by their sides, slightly widened the distance between their upper arms and trunk, adjusted the grip to the second knuckles of their fingers, and, with one hand, held the dynamometer with as much force as possible. Each arm was tested twice and the best score was recorded for each subject. Lower extremity muscle strength was tested with the subjects standing up from sitting in a chair and then sitting back down ${ }^{14)}$. Specifically, subjects sat in a chair with their arms folded across their chest, then stood up and sat down repeatedly for 30 seconds, the number of motions was counted. Upper extremity flexibility was tested with the subjects attempting to hold both hands together behind their back ${ }^{14)}$ with one hand above their shoulder and the other hand below the shoulder; the distance between the subjects' middle fingers was measured in centimeters and 
Table 2. Home-based exercises*

\begin{tabular}{|c|c|c|c|c|c|c|}
\hline $\begin{array}{l}\text { Warm up } \\
\text { program* }\end{array}$ & order & 1 & 2 & 3 & 4 & \\
\hline $\begin{array}{l}\text { Warm up } \\
\text { program* }\end{array}$ & movement & $\begin{array}{l}\text { back upright \& } \\
\text { slow deep } \\
\text { breathing }\end{array}$ & Neck extensor stretching & $\begin{array}{l}\text { Neck flexor } \\
\text { stretching }\end{array}$ & $\begin{array}{l}\text { xternal/intern } \\
\text { obiliqus st }\end{array}$ & $\begin{array}{l}\text { abdominal } \\
\text { tching }\end{array}$ \\
\hline $\begin{array}{l}\text { Warm up } \\
\text { program* }\end{array}$ & order & 5 & 6 & 7 & 8 & 9 \\
\hline $\begin{array}{l}\text { Warm up } \\
\text { program* }\end{array}$ & movement & shoulder exercises & back flexion/extension & $\begin{array}{l}\text { back \& scapular } \\
\text { stretching }\end{array}$ & runk rotation & heel - up \\
\hline $\begin{array}{l}\text { Warm up } \\
\text { program* }\end{array}$ & order & 10 & 11 & 12 & 13 & 14 \\
\hline $\begin{array}{l}\text { Warm up } \\
\text { program* }\end{array}$ & movement & wrist shaking & trapezius stretching & $\begin{array}{l}\text { gastrocnemius } \\
\text { stretching }\end{array}$ & $\begin{array}{l}\text { hip adductor } \\
\text { stretching }\end{array}$ & stand still \\
\hline $\begin{array}{l}\text { Warm up } \\
\text { program* }\end{array}$ & order & 15 & 16 & 17 & & \\
\hline $\begin{array}{l}\text { Warm up } \\
\text { program* }\end{array}$ & movement & shoulder rotation & neck circumduction & $\begin{array}{r}\text { external/internal abdomi1 } \\
\text { stretching }\end{array}$ & inal obiliquus & \\
\hline \multirow{6}{*}{$\begin{array}{l}\text { Exercises } \\
\text { program } * *\end{array}$} & order & 1 & 2 & 3 & \multicolumn{2}{|c|}{4} \\
\hline & movement & $\begin{array}{c}\text { heel raise } \\
\text { gastrocnemius } \\
\text { strengthing } \\
\end{array}$ & $\begin{array}{c}\text { knee extension } \\
\text { quardriceps femoris } \\
\text { strength }\end{array}$ & $\begin{array}{l}\text { hip flexion } \\
\text { hip flexor strength }\end{array}$ & \multicolumn{2}{|c|}{ stand still } \\
\hline & order & 5 & 6 & 7 & \multicolumn{2}{|c|}{8} \\
\hline & movement & $\begin{array}{l}\text { dance to routine } \\
\text { music }\end{array}$ & $\begin{array}{c}\text { knee flexion } \\
\text { quardriceps femoris } \\
\text { strength }\end{array}$ & $\begin{array}{l}\text { hip abduction } \\
\text { gluteus medius strength }\end{array}$ & \multicolumn{2}{|c|}{$\begin{array}{l}\text { hip flexion } \\
\text { hip flexor strength }\end{array}$} \\
\hline & order & 9 & 10 & 11 & \multicolumn{2}{|c|}{12} \\
\hline & movement & $\begin{array}{c}\text { dance to routine } \\
\text { music }\end{array}$ & $\begin{array}{l}\text { hip extension } \\
\text { gluteus maximus } \\
\text { strengthing } \\
\end{array}$ & $\begin{array}{l}\text { heel raise } \\
\text { balance }\end{array}$ & \multicolumn{2}{|c|}{ dance to routine music } \\
\hline \multirow{6}{*}{$\begin{array}{l}\text { Cool } \\
\text { down } \\
\text { program*** }\end{array}$} & order & 1 & 2 & 3 & \multicolumn{2}{|c|}{4} \\
\hline & movement & $\begin{array}{c}\text { neck flexor } \\
\text { stretching }\end{array}$ & neck extensor stretching & neck rotator stretching & \multicolumn{2}{|c|}{ deltoid stretching } \\
\hline & order & 5 & \multicolumn{2}{|c|}{6} & \multicolumn{2}{|c|}{7} \\
\hline & movement & $\begin{array}{l}\text { pectoralis major } \\
\text { stretching }\end{array}$ & \multicolumn{2}{|c|}{ internal/external abdominal obliquus stretching } & \multicolumn{2}{|c|}{$\begin{array}{l}\text { gluteus maximus \& } \\
\text { medius stretching }\end{array}$} \\
\hline & order & & 8 & 9 & \multicolumn{2}{|c|}{10} \\
\hline & movement & \multicolumn{2}{|c|}{ gluteus medius stretching } & $\begin{array}{c}\text { gastrocnemius \& } \\
\text { harmstring stretching }\end{array}$ & $\begin{array}{r}\text { adduct } \\
\text { stre }\end{array}$ & $\begin{array}{l}r \text { muscle } \\
\text { ching }\end{array}$ \\
\hline
\end{tabular}

* music : New Millennium Gymnastics music, times, every movement repeated 3 times ; ** music : K-pop, every movement repeated 18 times ;

*** stretching more than $10 \mathrm{sec}$, every movement repeated 3 times.

recorded. When subjects' fingers did not touch, the distance was recorded as a negative value, and when they passed each other, it was recorded as a positive value. Lower extremity flexibility was tested by having the subjects sit in a chair and bend forward ${ }^{14)}$. They were instructed to sit on the front part of the chair, bend one leg, and stretch the other leg, and stretch their hands as close as possible to their toes while bending at the waist. With the tips of the toes as the measurement point, when the finger tips crossed over the tips of the toes, the distance was recorded as a positive value, and when the finger tips did not cross over the tips of the toes, it was recorded as a negative value. Static balance ability was measured by instructing the subjects to close their eyes and stand on one leg ${ }^{14)}$. Subjects placed both hands on their waist, selected the leg they felt most comfortable standing on, and raised and bent the other leg. Then, the subjects closed their eyes, and the maximum time (in seconds) the subjects remained standing was measured. When their legs moved from the prescribed posture, measurement was stopped. An assistant stood nearby, without touching the subjects, to prevent them from falling. For cardiorespiratory endurance, the number of times subjects raised their knees to the midpoint between the patella and the iliac crest in 2 min was measured. When subjects raised their right knee to the prescribed height, this was counted as one motion; the motion was repeated for 2 minutes and the number of the motions was recorded ${ }^{14)}$. Total cholesterol was measured using the cholesterol oxidase-HDAOS method on a Hitachi 
Table 3. Changes in functional fitness and total cholesterol after 8 weeks of home-based exercise

\begin{tabular}{|c|c|c|c|c|}
\hline & group & before & after & Changes \\
\hline Upper muscle strength $(\mathrm{kg})$ & exercise* & $19.7 \pm 5.4$ & $21.5 \pm 6.3$ & $-1.1 \pm 2.6$ \\
\hline Upper muscle strength $(\mathrm{kg})$ & control & $22.5 \pm 5.3$ & $20.9 \pm 4.2$ & $1.6 \pm 2.8$ \\
\hline Lower muscle strength (times) & exercise* & $12.6 \pm 3.5$ & $17.1 \pm 7.7$ & $-4.4 \pm 5.7$ \\
\hline Lower muscle strength (times) & control & $11.9 \pm 1.9$ & $13.7 \pm 4.0$ & $-1.9 \pm 3.5$ \\
\hline Upper flexibility** $(\mathrm{cm})$ & exercise $^{* *}$ & $6.0 \pm 12.2$ & $4.6 \pm 13.2$ & $-2.4 \pm 5.0$ \\
\hline Upper flexibility** (cm) & control $^{*}$ & $11.7 \pm 13.7$ & $14.9 \pm 14.5$ & $0.8 \pm 1.9$ \\
\hline Lower flexibility (cm) & exercise* & $13.0 \pm 8.4$ & $18.2 \pm 6.2$ & $-2.5 \pm 2.1$ \\
\hline Lower flexibility $(\mathrm{cm})$ & control & $13.7 \pm 10.8$ & $13.5 \pm 11.2$ & $3.1 \pm 3.9$ \\
\hline Static balance (sec) & exercise & $5.4 \pm 8.3$ & $8.0 \pm 8.9$ & $-2.4 \pm 5.0$ \\
\hline Static balance (sec) & control* ${ }^{*}$ & $4.6 \pm 2.8$ & $3.8 \pm 1.5$ & $0.8 \pm 1.9$ \\
\hline Cardio-respiratory endurance** (times) & exercise $^{* *}$ & $93.3 \pm 20.3$ & $113.5 \pm 13.1$ & $-20.3 \pm 15.1$ \\
\hline Cardio-respiratory endurance** (times) & control* $^{*}$ & $90.6 \pm 18.6$ & $81.9 \pm 24.1$ & $8.7 \pm 9.1$ \\
\hline Total cholesterol (mg/dl) & exercise & $188.0 \pm 36.2$ & $186.4 \pm 38.5$ & $-20.3 \pm 15.1$ \\
\hline Total cholesterol (mg/dl) & control & $187.4 \pm 35.7$ & $193.1 \pm 25.1$ & $8.7 \pm 9.1$ \\
\hline
\end{tabular}

7600-110/7170 (Japan).

SPSS 18.0 was used to analyze the data and all variables are expressed as means and standard deviations. Each group's pre- and post-exercise differences were analyzed with the Wilcoxon signed-rank test, and the KolmogorovSmirnov test was employed to analyze differences between the two groups. A P-value $<0.05$ was considered statistically significant.

\section{RESULTS}

The results of the functional fitness analysis prior to and eight weeks after the home-based exercise program are listed in Table 3.

The exercise group showed a statistically significant improvement $(\mathrm{p}<0.05)$ in their upper extremity muscle strength, but the control group's muscular strength decreased without significance. For the lower extremity muscle strength, the exercise group's improvement was statistically significant $(\mathrm{p}<0.05)$, while the control group's improvement was not statistically significant. The exercise group's upper extremity flexibility significantly increased, evidenced by narrower distances between subjects' fingers $(p<0.01)$, but the control group's upper extremity flexibility significantly decreased $(p<0.05)$. The exercise group's lower extremity flexibility showed a statistically significant improvement $(p<0.05)$. The control group's lower extremity flexibility decreased, but without statistical significance.

In terms of the static balance ability test results, the exercise group's balance ability improved after the experiment (without statistical significance), and the control group's balance ability declined (statistically significant; $\mathrm{p}<0.05$ ). For cardiorespiratory endurance, the exercise group showed a statistically significant increase $(p<0.01)$ and the control group showed a statistically significant decrease $(p<0.05)$. With regard to changes in total cholesterol the exercise group did not show a significant change and the control group's total cholesterol levels slightly increased without statistical significance.

When comparing the two groups, there were statistically significant differences between the two groups' upper extremity flexibility $(\mathrm{p}<0.05)$ and cardiorespiratory endurance $(p<0.01)$ after the 8 weeks of exercise suggesting that the exercise group's upper extremity flexibility and cardiorespiratory endurance had improved compared to the control group.

\section{DISCUSSION}

This study examined the effects of a home-based exercise program on elderly women's physical fitness. The results indicate that the exercise group's upper extremity muscle strength and flexibility, lower extremity muscle strength and flexibility, and cardiorespiratory endurance improved, but those of the control group decreased. It was reported that a 12 -week home exercise program improved lower extremity muscle strength ${ }^{15}$, and a 12-week exercise using dumbbells and bands improved lower extremity muscle strength and arm force $(5 \%)^{16}$. In the present study, the exercise group's lower extremity muscle strength improved more than its upper extremity muscle strength, which is most likely due to the fact that the exercise program's main focus was on enhancing lower extremity muscle strength.

Flexibility declines with age, but may be improved through exercise, and it plays an important role in elderly people's activities of daily living and physical activities ${ }^{17)}$. Barbosa et al. (2002) ${ }^{18)}$ reported that a 10-week exercise program resulted in a $13 \%$ improvement in elderly people's flexibility, and Fatouros et al. (2002) ${ }^{19)}$ noted that subjects showed significant improvements in the flexibility of their pelvis, shoulders, and knees after a 16-week exercise program. In the present study, the flexibility of the exercise group's upper and lower extremities improved, but the control group's upper extremity flexibility decreased. This 
could be because stretching to improve flexibility was included in the warm-up and cool-down exercises, and enhanced the exercise subjects' flexibility. Nelson et al. ${ }^{20)}$ conducted a 6-month home exercise program focused on muscle strength, balance ability, and ordinary physical activities for community-dwelling elderly people (70 years of age or older), and verified improved dynamic balance in the exercise group. However, Schlicht et al. (2001) ${ }^{21)}$ conducted a similar study and found that their exercise group's changes in balance ability did not differ from the control group's, even though they performed muscle strength and aerobic exercises. In the present study, the exercise group showed improved static balance ability while the control group's static balance ability decreased. In a previous report, a 24-week regular exercise program resulted in significantly heightened cardiorespiratory endurance in subjects ${ }^{22)}$. In the present study, as well, there was improvement in the cardiorespiratory endurance of the exercise group while that of the control group declined. This result indicates that cardiorespiratory endurance, which rapidly declines with age, may be improved by physical exercise.

These results indicate that although physical fitness tends to drastically decline in elderly people, certain exercise programs may enhance elderly individuals' functional physical fitness. Accordingly, elderly people may maintain or even improve their physical fitness through continuous physical activities, but if they do not engage in regular exercise, their fitness levels can rapidly decline and ultimately speed the aging process. Prior research results on exercise and total cholesterol are highly inconsistent: regular aerobic exercise $\mathrm{e}^{23)}$ and a combination of aerobic and muscle resistance exercises ${ }^{24)}$ reduced total cholesterol levels, but endurance exercise did not significantly change total cholesterol levels ${ }^{25}$ ), and muscle resistance exercise did not result in a significant change in total cholesterol level ${ }^{26)}$. There was no significant change in total cholesterol levels in this study as well, possibly because total cholesterol is affected by diverse factors such as age, gender, ethnicity, body composition, blood pressure, degree of obesity, social and economic position, dietary pattern, and lifestyle ${ }^{27}$.

The home-based exercise program used in this study positively influenced elderly women's physical health and fitness levels, but a follow-up study is necessary to determine whether they continued to exercise on their own after the program. Moreover, a long-term research study should be conducted to verify the effects of exercise taking into consideration elderly people's specific exercise methods and intensity.

\section{REFERENCES}

1) Lim JH, Lee JO: The relationship between body composition change and muscle strength and endurance depending on aging at the senescence. J Korea Gerontolog Socie, 2001, 21: 15-24.

2) Kim CK, Lee WY, Bae YJ: The study of criterion for fitness in Korean elderly. Korean J Physi Edu, 2002, 39: 453-466.
3) Yoon $\mathrm{CH}$ : Effects of exercise program participation on skill related fitness in elderly adult. J Kore Socie Aerobic Exer, 2001, 5: 71-84.

4) Shin YH, Choi YH: The effect of walking exercise program on cardiorespiratory function and the flexibility in elderly women. J Kore Acade Nurs, 1996, 26: 372-386.

5) Choi SH.: The effects of exercise program on health of the elderly in senio citizen's center. J Kore Community Health Nurs Acade Socie, 1997, 11: $38-56$.

6) Ministry of Health and Welfare (2008). 2007 National health statistics: national health nutrition survey Quarternary Period (1st year).

7) Song MS, Song HJ: Development of community-based intensive health care program for the community dwelling elderly. J Kore Gerontologi Soci, 2009, 29: 37-50.

8) Bae JH.: The Effects of Physical Activity Participation on Health Fitnes Variable and Physical Self Description for Elderly Peoples. Kore Assoc School Physic Edu, 2004, 14: 13-23.

9) Kim HS: The effect of progressive low intensity exercise on the activities and functional performance of the elderly. The catholic university of korea, doctor's thesis, 2000.

10) Han MJ, Lee YS, Koo SJ: The study of food habit and degree of depression in nursing home and privite home living elderly. J Kore Socie Diet Cultu, 1998, 13: 475-487.

11) National Institute on Aging: http://www.nia.nih.gov/.

12) Borg G: Borg's perceived exertion and pain scales. Illinois: Hum Kinetics, 1998, pp 13-16.

13) Han YS, Lee SJ: Effects of combined exercise program for 8 weeks on physical fitness in elderly farmers. Kore J Growth Dev, 2008, 16: 313-318.

14) Rikli RE, Jones CJ: Senior Fitness Test Manual. Illinois: Hum Kinetics, 2001, pp 80-94.

15) Gardner MM, Phty M, Robertson MC, et al.: Application of a falls prevention program for older people to primary health care practice. Prev Med, 2002, 34: 546-553. [Medline] [CrossRef]

16) Rogers ME, Sherwood HS, Rogers NL, et al.: Effects of dumbbell and elastic band training on physical function in older inner city AfricanAmerican women. Women Health, 2002, 36: 33-41. [Medline] [CrossRef]

17) Morley JE, Kaiser FE, Perry MH 3rd, et al.: Longitudinal changes in testosterone, luteinizng hormone, and follicle-stimulating hormone in healthy older men. Metabolism, 1997, 46: 410-413. [CrossRef]

18) Fatouros IG, Taxildaris K, Tokmakidis SP, et al.: The effects of strength training cardiovascular training and there combination on flexibility of in active older adults. Int J Sports Med, 2002, 23: 112-119. [Medline] [CrossRef]

19) Messier SP, Royer TD, Craven TE, et al.: Long term exercise and its effect on balance in older, osteoarthritic adults. J Am Geriatr Soc, 200, 48: 131138.

20) Nelson ME, Layne JE, Bernstein MJ, et al.: The effects of multidimensional home-based exercise on functional performance in elderly people. J Gerontol A Biol Sci Med Sci, 2004, 59: M154-M160. [Medline] [CrossRef]

21) Schlicht J, Camaione DN, Owen SV: Effect of intense strength training on standing balance, walking speed and sit-to-stand performance in older adults. J Gerontol A Biol Sci Med Sci, 2001, 56: M281-286. [Medline] [CrossRef]

22) Kim HJ, Kim SW.: The influence of regular exercise for 24 weeks on the factors related fitness of the old ages. Kore sport resear, 2005,16: 641-652.

23) Lee JG: The effects of aerobic exercise and obese education on the body composition in obese girls' high school students. J Kore Socie Study Physi Edu, 2003, 7: 219-230.

24) Park TG, Choi WS: Effects of aerobic combined with resistance training on body composition and blood lipids in obese middle-aged women. Kore J Physi Edu, 2005, 44: 1141-1149.

25) Stein RA, Michielli DW, Glantz MD, et al.: Effects of different exercise training intensities on lipoprotein cholesterol fractions in healthy middleaged men. Am Heart J, 1990, 119: 277-283. [Medline] [CrossRef]

26) Lee SW, Kim BH, Seo HG, et al.: The effects of muscular resistance training on body composition and physical fitness in women. Korean Soc Sports Med, 1999, 17: 197-203.

27) Weimann E, Blum WF, Witzel C, et al.: Hypoleptinemia in females and male elite gymnasts. Eur J Clin Invest, 1999, 29: 853-860. [Medline] [CrossRef] 